\title{
Design of Fast-Response On-Chip Current Sensor for Current-Mode Controlled Buck Converters with $\mathrm{MHz}$ Switching Frequency
}

\author{
Tsz Yin Man, Philip K. T. Mok and Mansun Chan
}

\begin{abstract}
In this work, techniques to design fast-response on-chip current sensor for buck converter (BC) with MHz-range switching frequency is successfully developed. Unwanted voltage spike at the sensor output, which not only degrades the response time of sensor but also interrupts the operation of $\mathrm{BC}$, is minimized by carefully controlling the activation and deactivation time of current sensor. Response time of sensor is also improved by specially designed error amplifier, which provides large slew-rate in both positive and negative direction during transient response and consumes only small quiescent current at steady-state operation. Sensing accuracy at small inductor current is also improved in the proposed design. It is shown that the proposed current sensor is able to respond to a $\mathrm{BC}$ with $10 \mathrm{MHz}$ switching frequency at only 8 - $\mu \mathrm{A}$ quiescent current consumption.
\end{abstract}

\section{INTRODUCTION}

Buck converters (BCs) are widely used in battery-powered mobile systems due to their superior power efficiency and also the increasing use of low-supply-voltage circuits, which are intended to lower power consumption of mobile systems. To enable BCs with fast dynamic response and also over-current protection, current-mode control is used. Inductor current is required to be acquired in current-mode controlled BCs. Among different inductor current sensing techniques, on-chip current sensor [1-3] based on the transistor-scaling technique [4] is often used in current-mode controlled BCs. However, requirements of $\mathrm{BCs}$ in nowadays mobile systems make the design of current sensor very challenging. The need of small off-chip inductor for printed circuit board (PCB) space reduction makes $\mathrm{BCs}$ to operate at several $\mathrm{MHz}$ [5-7] or even at tens to thousands $\mathrm{MHz}$ [8-10]. The continuously scaled supply voltage of circuits used in mobile systems, but not the battery voltage, reduces duty cycle of $\mathrm{BCs}$ and hence the conduction time of the main switch. Both the high switching frequency and the reduced main switch conduction time inevitably impose response-time constraint on the current sensor design. As a result, techniques to design fast-response on-chip current sensor is definitely required and worth to develop.

In this paper, techniques to design fast-response on-chip current sensor is successfully developed and thoroughly discussed. Section II first discusses the response-time limits

Tsz Yin Man, Philip K. T. Mok and Mansun Chan are with the Department of Electronic and Computer Engineering, the Hong Kong University of Science and Technology, Clear Water Bay, Kowloon, Hong Kong, E-mail: eesm $a$ ece.ust.hk of existing designs. Then the proposed design and its advantages are introduced. Results and discussions are shown in Section III. Finally, conclusion is given in Section IV.

\section{DESIGN OF FAST-RESPONSE ON-CHIP CURRENT SENSOR}

\section{A. Response-Time Limits}

To successfully develop techniques to design fast-response on-chip current sensor, it is necessary to understand the response-time limits of existing designs. Fig. 1 shows the schematic of a generic current sensor used in a current-mode controlled BC. Switches $S_{1}$ and $S_{2}$ are used to activate and deactivate the current sensor by connecting the inverting input of error amplifier $\left(V_{M}\right)$ to either the switching node $\left(V_{X}\right)$ or the input $\left(\mathrm{V}_{\mathrm{IN}}\right)$ of $\mathrm{BC}$. When the main power transistor $\left(\mathrm{M}_{\mathrm{MAIN}}\right)$ is on, the current sensor is activated by turning on switch $\mathrm{S}_{1}$ and off switch $\mathrm{S}_{2}$. Negative feedback forces the non-inverting input of error amplifier $\left(V_{P}\right)$ tracked with the $V_{M}$ node. As size of the sensing transistor $\left(\mathrm{M}_{\mathrm{SEN}}\right)$ and the $\mathrm{M}_{\mathrm{MANN}}$ is in ratio (e.g. 1:1000), inductor current is down scaled and reproduced by the $\mathrm{M}_{\mathrm{SEN}}$, and is converted to voltage by the sensing resistor $\left(\mathrm{R}_{\mathrm{SEN}}\right)$. Once the $\mathrm{M}_{\mathrm{MAIN}}$ is off, current sensor is deactivated by switching off $S_{1}$ and on $S_{2}$ so that the drain-to-source voltage of $\mathrm{M}_{\mathrm{SEN}}$ is forced to zero by negative feedback of the error amplifier (EA). As negligible current flows through $\mathrm{M}_{\mathrm{MAIN}}$ and hence $\mathrm{M}_{\mathrm{SEN}}$, voltage developed the $\mathrm{V}_{\mathrm{SEN}}$ node is therefore close to zero.

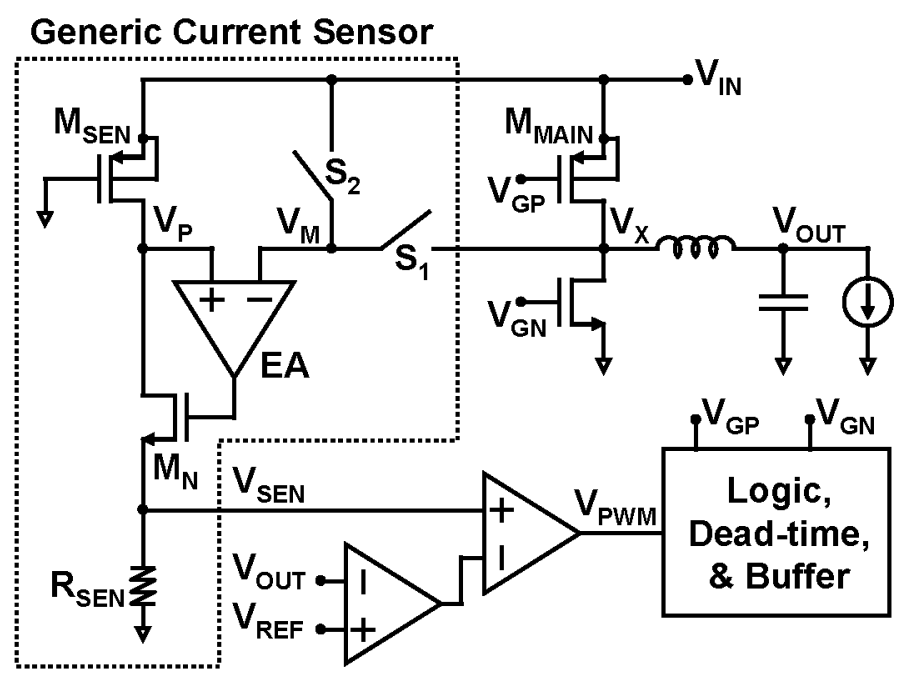

Fig. 1 Schematic of a generic current sensor used in current-mode controlled buck converter. 


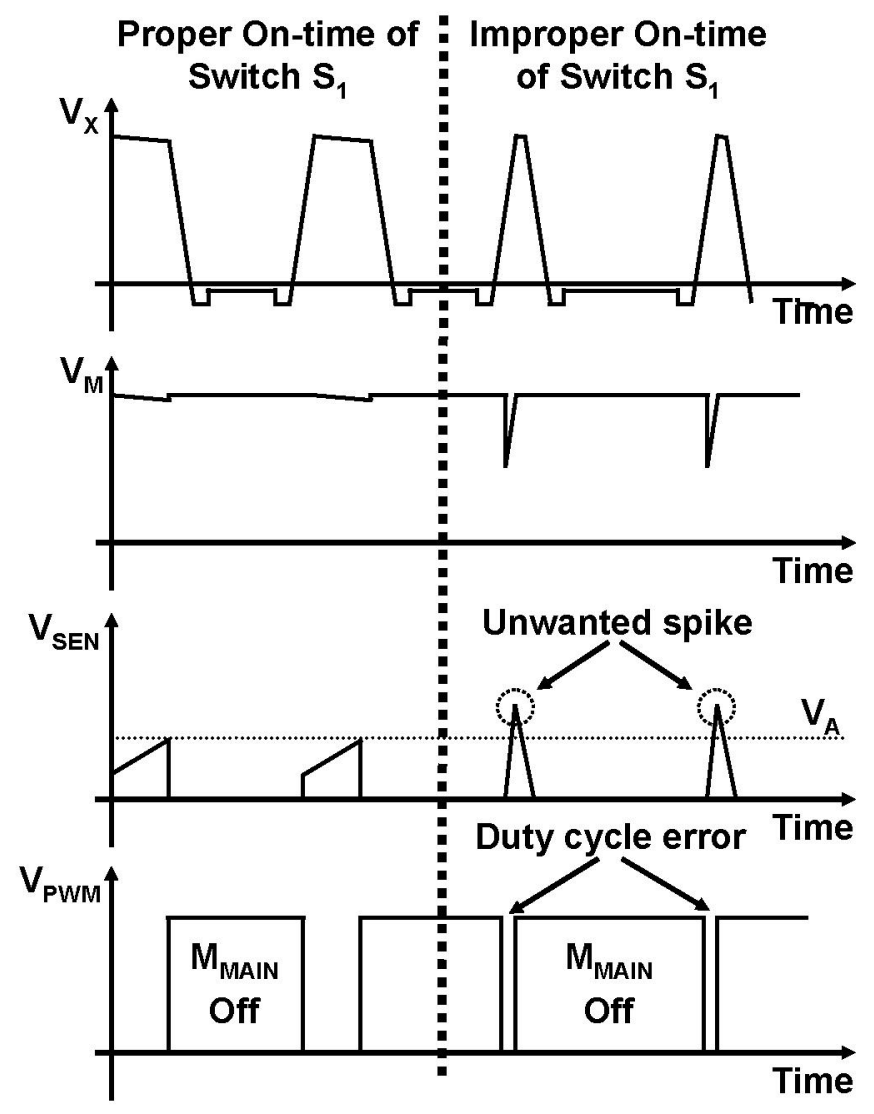

Fig. 2 Impact of improper switching time of switch $S_{1}$ on the operation of current-mode controlled BC.

Although function of those switches is very simple, the time to switch them on and off not only has a great impact on the response time of current sensor but also the control of $\mathrm{BC}$. When the $M_{\mathrm{MAIN}}$ is on, the $\mathrm{V}_{\mathrm{X}}$-node voltage is pulled from approximately zero volt to almost $V_{\Pi \mathrm{N}}$. It is necessary to ensure the $S_{1}$ is on and $S_{2}$ is off at the time where $V_{X}$ is settled. Otherwise, any intermediate $V_{X}$-node voltage (e.g. $\left.V_{I N} / 2\right)$ is possible to be sampled and misinterpreted by the current sensor as very-large inductor current. Response time of current sensor is hence degraded as extra period of time is required by the sensor to settle from a misinterpreted large value to the actual value. More seriously, this misinterpreted large value is possible to trigger the current-mode controller to turn off the $\mathrm{M}_{\text {MAIN }}$ early than what supposing to be. This is illustrated in Fig. 2. In similar manner, switch $\mathrm{S}_{1}$ should be off and $\mathrm{S}_{2}$ should be on before the $\mathrm{M}_{\text {MAIN }}$ is ordered to fully turn off by the controller. Otherwise, the current sensor is possible to misinterpret a large inductor current again.

Another response-time limit is caused by the slew-rate of the EA. When every cycle the $V_{M}$ node is routed from the $V_{X}$ node to the $V_{\mathrm{N}}$ node and vice versa, a voltage step is appeared at the $V_{M}$ node. The EA is forced to either charge or discharge the gate of $\mathrm{M}_{\mathrm{N}}$ by negative feedback until the $\mathrm{V}_{\mathrm{P}}$-node voltage is tracked with the $\mathrm{V}_{\mathrm{M}}$-node voltage. This delay time depends on the slew rate (SR) of EA that is expressed in equation (1)

$$
\mathrm{SR}=\frac{\mathrm{I}_{\text {EAMAX }}}{\mathrm{C}_{\mathrm{GMN}}}
$$

where $\mathrm{I}_{\text {EAMAX }}$ is the maximum output current of $\mathrm{EA}$, and $\mathrm{C}_{\mathrm{GMN}}$ is the gate capacitance of the transistor $\mathrm{M}_{\mathrm{N}}$.

However, conventional EA with tail-current bias has a very strong tradeoff between its slew-rate and its quiescent-current consumption. This is because $\mathrm{I}_{\text {EAMAX }}$ of such EA is limited by its tail current. As a result of it, current sensor in [1] and [3] with tail-current-biased EA is not suitable for $\mathrm{BC}$ with MHz-range switching frequency.

In [2] and [4], voltage mirror instead of conventional EA is used in the current sensor to force the $\mathrm{V}_{\mathrm{P}}$-node voltage tracking with the $\mathrm{V}_{\mathrm{M}}$-node voltage. The corresponding schematic is shown in Fig. 3. It is observed that drain current of $M_{1}$ to charge the gate of $\mathrm{M}_{\mathrm{N}}$ can be much larger than the value of biasing current $\left(\mathrm{I}_{B}\right)$ when the $\mathrm{V}_{\mathrm{M}}$ node is just routed from the $\mathrm{V}_{\mathrm{IN}}$ node to the $\mathrm{V}_{\mathrm{X}}$ node. However, the current to discharge the gate of $M_{N}$ is fixed and defined by the $I_{B}$. It means that such current sensor can only have fast response on a sudden increase but not a sudden decrease inductor current.

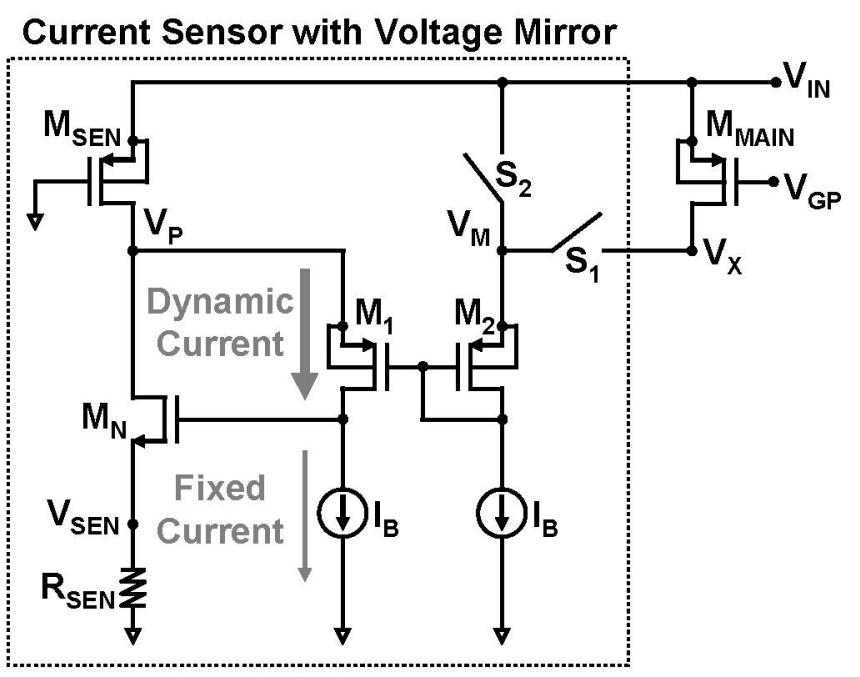

Fig. 3 Schematic of current sensor with voltage mirror having asymmetrical response time.

\section{B. Proposed Design}

To enable a fast-response current sensor without the aforementioned limits, it is necessary to control the time to switch $S_{1}$ and $S_{2}$ and to develop an error amplifier with high slew-rate and low quiescent current consumption. Fig. 4 shows the proposed current sensor. Both the switches $S_{1}$ and $\mathrm{S}_{2}$ are implemented by PMOS transistors. To achieve the on an off time of switch $S_{1}$ mentioned before, the gate of switch $S_{1}$ is connected to the gate of $M_{\text {MAIN. }}$ For the switch $S_{2}$, its gate is connected to the intermediate stage of the buffer used to drive the $\mathrm{M}_{\mathrm{MAIN}}$ as shown in Fig. 4. This connection makes $S_{2}$ tuned off before the $S_{1}$ turned on, from which the $V_{M}$ node is much easier to be pulled down when $S_{1}$ is on. 

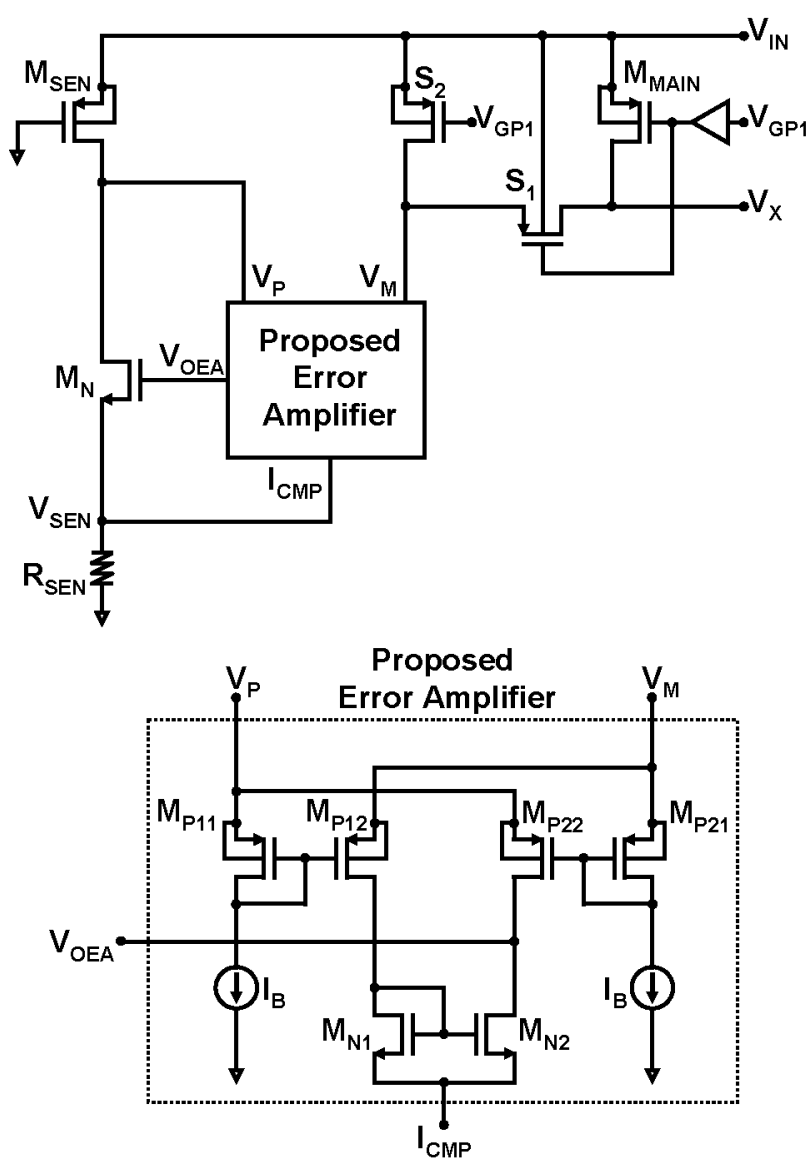

Fig. 4 Schematic of proposed current sensor.

As $S_{2}$ is on before the $S_{1}$ turned off, it is guaranteed that the $\mathrm{V}_{\mathrm{M}}$-node voltage can be quickly pulled up to the level of $\mathrm{V}_{\mathrm{NN}}$ when $S_{1}$ is off. This prevents unwanted voltage spikes at the current sensor output when the $\mathrm{M}_{\mathrm{MANN}}$ is off.

The error amplifier used in the proposed current sensor is constructed by two constant current sources $\left(\mathrm{I}_{\mathrm{B}}\right)$, two current mirrors with matched PMOS transistors in cross-coupled connection, and one current mirror with matched NMOS transistors. When the $V_{M}$ node is routed from the $V_{\mathbb{I N}}$ node to the $V_{X}$ node, transistor $M_{P 22}$ can provide larger current, which is much larger than the value of $\mathrm{I}_{\mathrm{B}}$, to quickly charge the gate of $M_{N}$. Once the $V_{M}$ node is routed from the $V_{X}$ node to the $V_{\mathrm{IN}}$ node, a current larger than $\mathrm{I}_{\mathrm{B}}$ can be provided by transistor $\mathrm{M}_{\mathrm{P} 12}$. With the current mirror constructed by two matched NMOS transistors $\left(\mathrm{M}_{\mathrm{N} 1}\right.$ and $\left.\mathrm{M}_{\mathrm{N} 2}\right)$, this large drain current of $\mathrm{M}_{\mathrm{P} 12}$ is redirected to quickly discharge the gate of $\mathrm{M}_{\mathrm{N}}$. When the $\mathrm{V}_{\mathrm{P}}$-node voltage is tracked with the $\mathrm{V}_{\mathrm{X}}$-node voltage, current of both the $\mathrm{M}_{\mathrm{P} 12}$ and the $\mathrm{M}_{\mathrm{P} 22}$ is defined by the constant current source $I_{B}$. As a result of it, the proposed design is able to have large slew-rate at transient response and low quiescent current consumption at steady-state operation. Moreover, large slew-rate in both positive and negative direction is achieved. Therefore, symmetrical response time is successfully achieved in the proposed current sensor.
Another advantage of the proposed current sensor is its improved accuracy on sensing small inductor current. As shown in Fig. 4, part of the current of $\mathrm{M}_{\mathrm{SEN}}$ is used by the error amplifier. If the current of $\mathrm{M}_{\mathrm{SEN}}$ is very small, it is possible that the current injected into the $\mathrm{R}_{\mathrm{SEN}}$ is much smaller than that of $\mathrm{M}_{\mathrm{SEN}}$. Large error is occurred. To minimize this error, part of the current used by the error amplifier is reused and injected into the $R_{\mathrm{SEN}}$. This can be easily understood by steady-state analysis. In steady-state operation, the $\mathrm{V}_{\mathrm{P}}$-node voltage is well tracked with the $\mathrm{V}_{\mathrm{M}}$-node voltage. It means that current of all transistors inside the error amplifier is very close to the value defined by the current source $I_{B}$. As the error amplifier consumes $2 \mathrm{xI}_{\mathrm{B}}$ current from the $\mathrm{M}_{\mathrm{SEN}}$, source terminal of transistors $\mathrm{M}_{\mathrm{N} 1}$ and $\mathrm{M}_{\mathrm{N} 2}$ are connected to the $\mathrm{R}_{\mathrm{SEN}}$ such that $2 \mathrm{xI}_{\mathrm{B}}$ current is injected into the $\mathrm{R}_{\mathrm{SEN}}$. Therefore, current of $R_{S E N}$ becomes very close to that of $M_{S E N}$. Accuracy on sensing small inductor current is hence improved.

\section{RESULTS AND DISCUSSIONS}

The proposed current sensor is designed in a $0.35-\mu \mathrm{m}$ CMOS process. To minimize the power consumption, size of $M_{\text {SEN }}$ is designed to be one thousand times smaller than that of $\mathrm{M}_{\text {MAIN }}$. The $\mathrm{R}_{\mathrm{SEN}}$ is designed to be $500 \Omega$ so that $0.5 \mathrm{~V}$ at the $\mathrm{V}_{\mathrm{SEN}}$ node represents $1 \mathrm{~A}$ of inductor current flowing through the $\mathrm{M}_{\text {MAIN }}$. The current source $\mathrm{I}_{\mathrm{B}}$ is designed to be $2 \mu \mathrm{A}$. To reduce quiescent current consumption, size of $\mathrm{M}_{\mathrm{P} 12}$ and $\mathrm{M}_{\mathrm{P} 22}$ is set to be the same as that of $\mathrm{M}_{\mathrm{P} 11}$ and $\mathrm{M}_{\mathrm{P} 21}$. Total quiescent current consumed by the error amplifier is only $8 \mu \mathrm{A}$. Table I summarize the size ratio of transistors inside the proposed current sensor.

To exam the response time of the proposed current sensor, extensive simulations are done. Fig. 5 shows the simulated result where the current sensor is in a $\mathrm{BC}$ with $2.7-\mathrm{V} \mathrm{V}_{\mathrm{IN}}$ (e.g. minimum voltage of lithium battery), $0.9-\mathrm{V}$ output, and $4-\mathrm{MHz}$ switching frequency. It is shown that the output of current sensor is quickly jumped from zero volt to $\sim 0.22 \mathrm{~V}$ that represents the $\sim 440-\mathrm{mA}$ minimum inductor current. The output of current sensor is able to track with the increasing inductor current and quickly jump from $\sim 0.31 \mathrm{~V}$, which represents the $\sim 620-\mathrm{mA}$ peak inductor current, to zero volt. It is observed that unwanted voltage spike is greatly minimized. To further exam the response time of current sensor, the switching frequency is increased from $4 \mathrm{MHz}$ to $10 \mathrm{MHz}$. As shown in Fig. 6, the current sensor still responds quickly at only $8-\mu \mathrm{A}$ quiescent current.

TABLE I

Size Ratio of Transistors of Proposed Current Sensor

\begin{tabular}{|c|c|}
\hline Transistors & Ratios \\
\hline $\mathrm{M}_{\mathrm{MANN}}: \mathrm{M}_{\mathrm{SEN}}: \mathrm{S}_{1}: \mathrm{S}_{2}$ & $1000: 1: 1: 1$ \\
\hline $\begin{array}{c}\mathrm{M}_{\mathrm{P} 11}: \mathrm{M}_{\mathrm{P} 12}, \mathrm{M}_{\mathrm{P} 21}: \mathrm{M}_{\mathrm{P} 22}, \\
\mathrm{M}_{\mathrm{N} 1}: \mathrm{M}_{\mathrm{N} 2}\end{array}$ & $1: 1$ \\
\hline
\end{tabular}



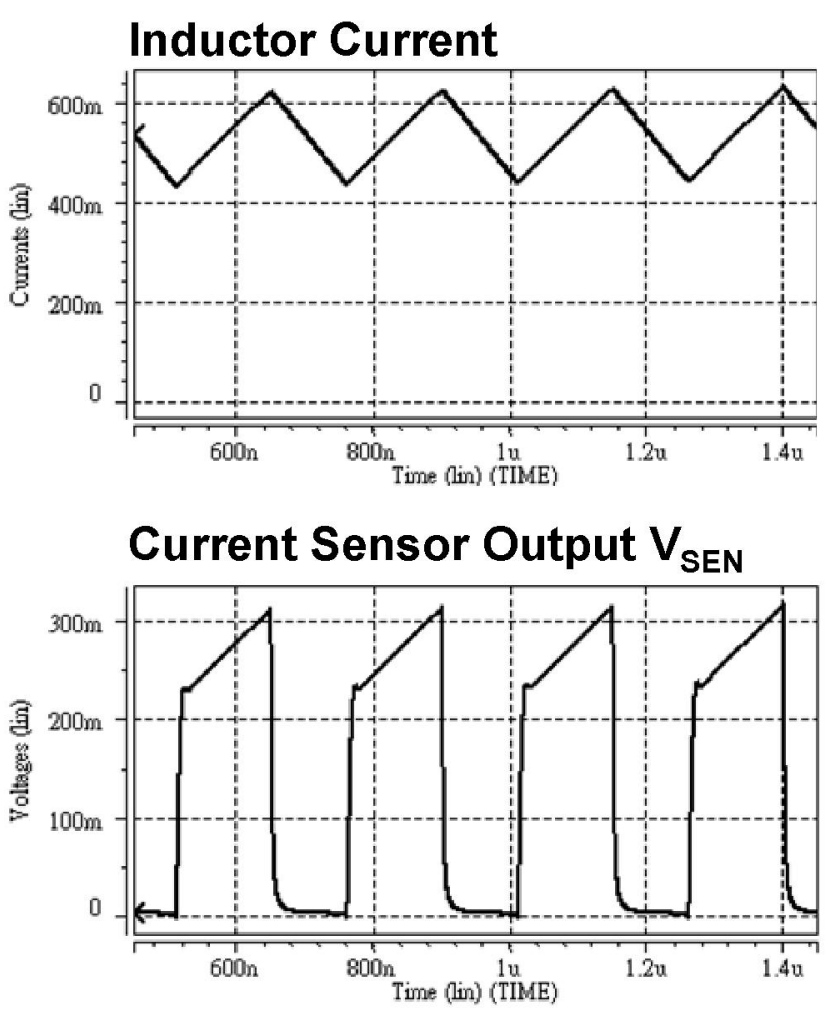

Fig. 5 Simulated response of proposed current sensor in a buck converter operating at $4 \mathrm{MHz}$.

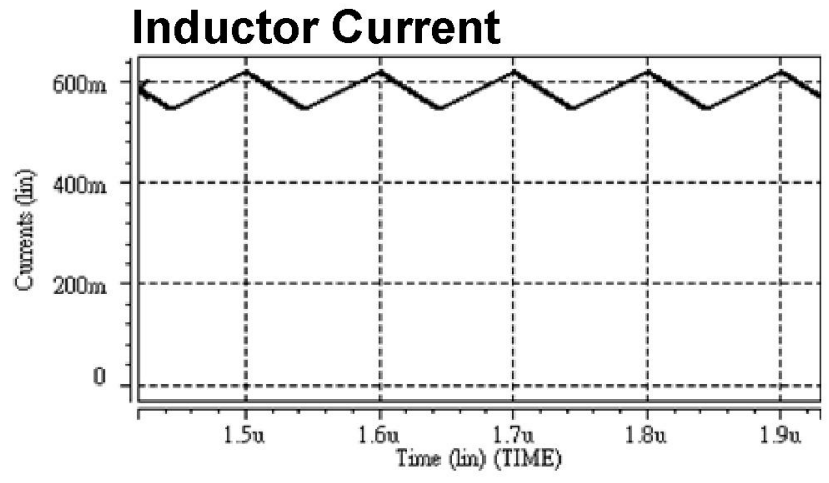

\section{Current Sensor Output $\mathrm{V}_{\text {SEN }}$}

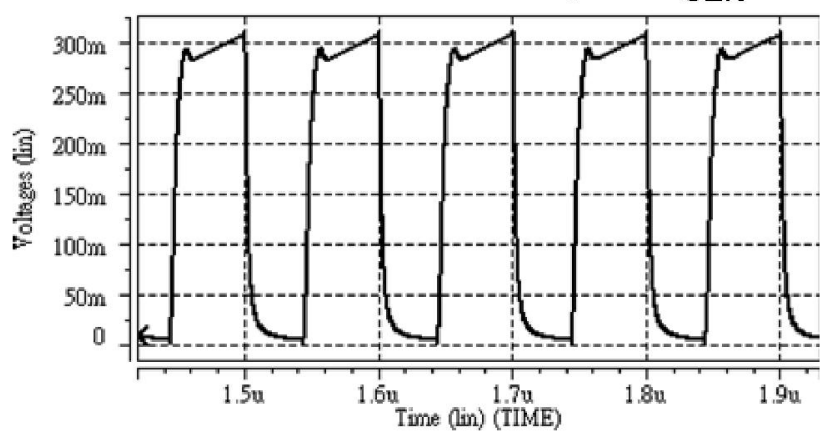

Fig. 6 Simulated response of proposed current sensor in a buck converter operating at $10 \mathrm{MHz}$.

\section{CONClusion}

Techniques to design fast-response on-chip current sensor applied in $\mathrm{MHz}$-switching $\mathrm{BC}$ are successfully developed. The first technique minimizes the voltage spike, which occurs at the sensor output when it is started or disable, by carefully control both its activation and deactivation time. This voltage-spike minimization helps to prevent regulation error. Another technique enables the error amplifier used in the sensor with large slew-rate in both pull-up and down direction with very low quiescent current consumption. Response time of current sensor is greatly improved without huge power consumption. The reuse of part of error amplifier quiescent current also helps to improve the sensor accuracy, especially when the inductor current is small. As a result of them, the proposed current sensor is very applicable to switching converters with very high switching frequency or to an application where accurate current waveform is required for control purpose or information acquisition.

\section{ACKNOWLEDGEMENT}

This work was supported by the Research Grant Council of Hong Kong SAR Government, China, under project No. 617705 .

\section{REFERENCES}

[1] C. F. Lee and P. K. T. Mok, "A monolithic current-mode CMOS dc-dc converter with on-chip current-sensing technique," IEEE Journal of Solid-State Circuits, vol. 39, pp. 3-14, January 2004.

[2] Y.-H. Lam, W.-H. Ki and D. Ma, "Loop gain analysis and development of high-speed high-accuracy current sensors for switching converters," IEEE International Symposium on Circuits and Systems, vol. V, pp. 828-831, May 2004.

[3] C. Y. Leung, P. K. T. Mok, K. N. Leung and M. Chan, "An integrated CMOS current-sensing circuit for low-voltage current-mode buck regulator," IEEE Transactions on Circuits and Systems II, vol. 52 , pp. 394-397, July 2005.

[4] W. H. Ki, "Current sensing technique using MOS transistors scaling with matched bipolar current sources," U.S. Patent 5,757,174, May 26, 1998.

[5] E. Bonizzoni, F. Borghetti, P. Malcovati, F. Maloberti and B. Niessen, "A $200 \mathrm{~mA} 93 \%$ peak efficiency single-inductor dual-output dc-dc buck converter," IEEE International Solid-State Circuits Conference, pp. 526-527, February 2007.

[6] M. Mulligan, B. Broach and T. Lee, "A 3MHz low-voltage buck converter with improved light load efficiency," IEEE International Solid-State Circuits Conference, pp. 528-529, February 2007.

[7] D. Ma, W.-H. Ki and C.-Y. Tsui, "An integrated one-cycle control buck converter with adaptive output and dual-loop output error correction," IEEE Journal of Solid-State Circuits, vol. 39, pp. 140-149, January 2004.

[8] M. Alimadadi, S. Sheikhaei, G. Lemieux, S. Mirabbasi and P. Palmer, "A $3 \mathrm{GHz}$ switching de-de converter using clock-tree charge-recycling in $90 \mathrm{~nm}$ CMOS with integrated output filter," IEEE International Solid-Siate Circuits Conference, pp. 532-533, February 2007.

[9] P. Hazucha, G. Schorm, J. Hahn, B. A. Bloechel, P. Hack, G. E. Dermer, S. Narendra, D. Gardner, T. Karnik, V. De, and S. Borkar, "A 233-MHz $80 \%-87 \%$ efficient four-phase dc-dc converter utilizing air-core inductors on package," IEEE Journal of Solid-State Circuits, vol. 40, pp. 838-845, April 2005.

[10] S. K. Reynolds, "A de-de converter for short-channel CMOS technologies," IEEE Journal of Solid-State Circuits, vol. 32, pp. 111-113, January 1997. 